\title{
Looking at Organic Nanoparticles with SEM, CRIO-SEM and HRSEM.
}

\author{
H. A. Zavaleta-Mancera*, G. Hanako*, Efrén Ramírez-Bribiesca**, A. Romero-Pérez**, E. \\ García-García** and S. Clayton Wade**** \\ *Electron Microscopy Unit, **Livestock Department. Postgraduate College in Agriculture. \\ Montecillo, Edo. Mex. México.Km. 36.5 Carretera México Texcoco. \\ ***Psicofarma Laboratory, Calzada de Tlalpan, D.F. México. \\ ****Advanced Microscopy and Bio-Imaging Laboratory, University of Wales, Aberystwyth UK.
}

Observation of organic nanoparticles is always a challenge, since the particles

are made of with non conductive substance [1]. The present work investigates three electron microscopy techniques, SEM, SEM-CRIO and HRSEM for morphological characterization of organic nanoparticles of Se-Eudragit. Variables such as: sample dilution, centrifugation, air dry, metal coating and non-coating were tested on sample preparation. Detection of backscattered electrons combined with secondary electrons detection was experimented under different electron microscope working conditions $(\mathrm{kV}, \mathrm{WD}$, etc.). The advantages and disadvantages of the techniques are discussed.

Sodium selenite was encapsulated by nano-precipitation and emulsion-evaporation methods, within polymeric Eudragit RL and RS using ethanol and acetone as solvents [2]. After physical characterization, an aliquot $10 \mu \mathrm{L}$ of nanoparticles + polymer (Eudragit) were dispersed in $1 \mathrm{~mL}$ of deionizer water (DI).

Technique 1. Conventional high vacuum SEM. a) A volume of $20 \mu$ of the diluted (1:1000) sample was air-dried on a cooper studs, and coated with gold using a Ion Sputter JFC-III00 (JeolJapan. A) Particles were diluted to 1:100 then they were centrifuged at 27, $000 \mathrm{rpm}$ for $60 \mathrm{~min}$, the pellet was re-suspended in $10 \mathrm{~mL}$ of DI water. B) a aliquot of $10 \mu \mathrm{L}$ of each nano-particle solution, were dispersed in $1 \mathrm{~mL}$ of deionizer water, and then a drops $(20 \mu \mathrm{L})$ was paced on a cooper stud and air-dried. The sample was gold coated with gold (Ion Sputter JFC-III00). Observations were made in a JSM-6390 (Jeol-Japan) at the Electron Microscopy Unit of COLPOS, Mexico.

Technique 2. SEM-CRIO. A drop $(20 \mathrm{uL})$ of the concentrated nanoparticles suspension was placed in a fine cylinder ( $1 \mathrm{~mm}$ diameter) and under liquid $\mathrm{N}_{2}$ then a free fracture was produced with a snap (specially designed machine, University of Wales maker) under low temperature. Exposed face of fracture was observed under a conventional SEM-CRIO, Jeol in a high vacuum chamber, and images were produced with secondary electrons.

Technique 3 . HRSEM, High resolution Microcopy at low vacuum. Organic particles were centrifuged at $13000 \mathrm{rpm} / 5 \mathrm{~min}$, diluted to 1/1000 in deionizer distilled water. An aliquot of 10 $\mathrm{mL}$ was placed on a smooth round glass slide and ion-coated with platinum-palladium. Then particles without coating, were observed with a Hitachi S-4100 Field Emission SEM at the "Advance Microscopy and Imaging Unit" of the University of Wales, Aberystwyth. Experimentation consisted on testing acceleration voltage (1.0, 1.5, 3.0 and 6,0 KV), WD and combination of secondary electrons with back scattered electron detection under different working conditions.

\section{References}

[1] G.Rh Owen, M. Kääb and K. Ito. Scanning Microscopy 13 (1999) 83-91.

[2] A, Romero-Pérez, et al., Vet. Res.Commun. 34 (2010) 71-79. 
Morphological characterization of organic Eudragit polymer nano-particles were adequately observed using HRSEM at $1.5 \mathrm{kV}$ under variable pressure, using secondary + back scattered electron detection. In our experience reducing voltage, $(1.5 \mathrm{Kv}$ and combining with $\mathrm{BS}$ detection on a conductive holder (platinium-paladium base coating) produce better image ${ }^{\mathrm{S}}$ with increased resolution for morphology characterization.

Aknowledgements. The authors thank the economic support from the Line of Research (LPI-16 Innovación Tecnológica) of the Colegio de Postgraduados, México. Also we want to recognize Iolo ap Gwynn (PhD) and Stephen Clayton Wade (PhD) for the High Resolution Electron Microscopy facilities provided at the University of Wales.

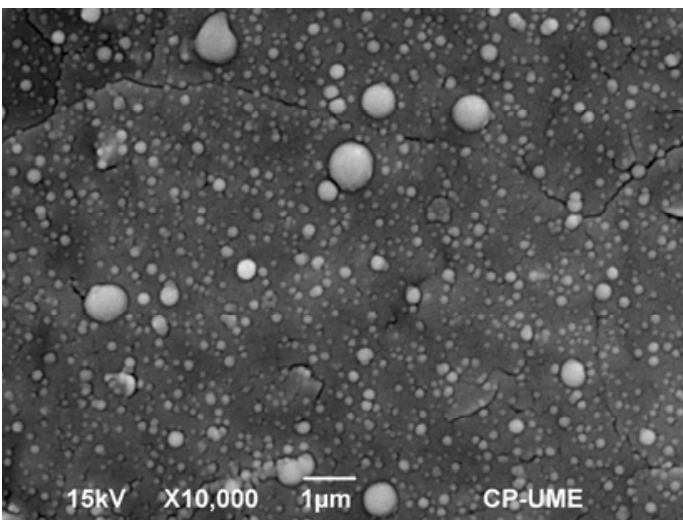

Technique 1A. SEM-high vacuum. Polymer was not disposed by centrifugation. Particles appeared immersed in the polymer Eudragit. And difficult to characterize. $15 \mathrm{kV} \times 10,000$. Gold coating.

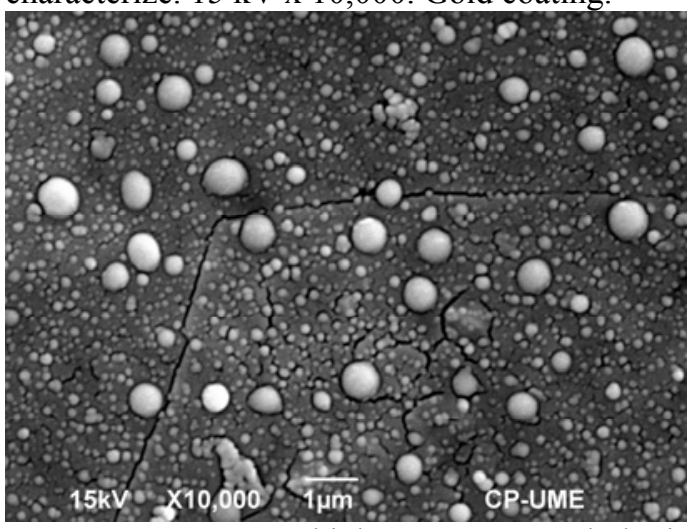

Technique 1B. SEM-high vacuum. Morphological characterization is possible (measurements and description). JSM-6390 JEOL at $15 \mathrm{kV}$ x 10,000.

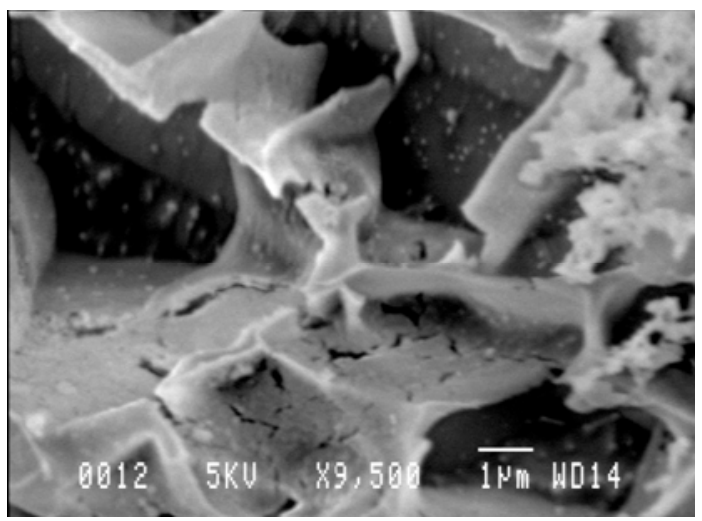

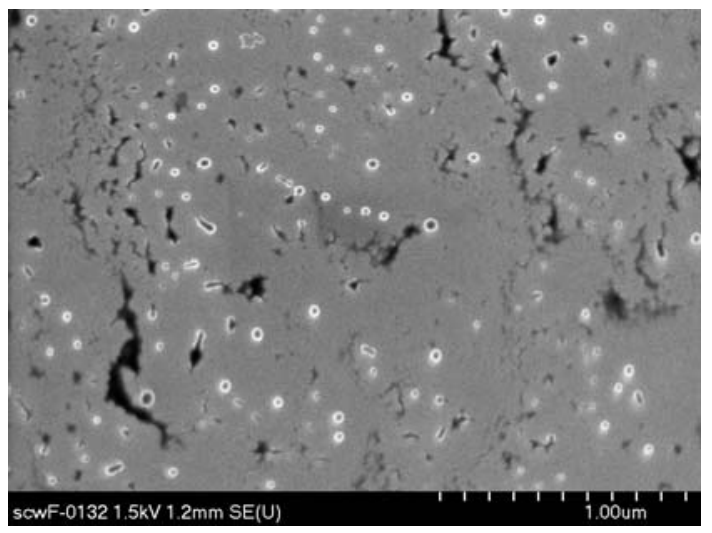

Technique 3. HRSEM of no-coating particles. Voltage used did not give information of the surface morphology. Seconday +back scattered electrons, $3.0 \mathrm{Kv}$ at $1.2 \mathrm{~mm} \mathrm{WD}$

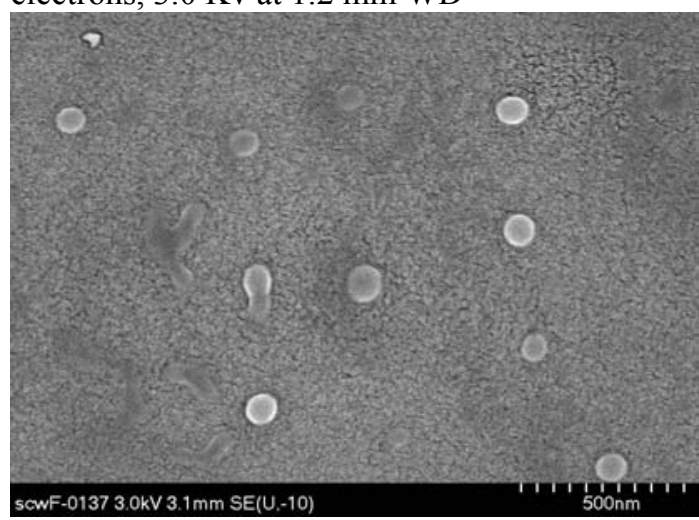

Technique 3. HRSEM of no-coated particles. Selected method for characterization of no-coating organic (Eudragit) nano particles.Secondary + back scattered electrons. $1.5 \mathrm{kV}, 3.1 \mathrm{WD}$

Technique 2. SEM Low temperature. Cryo-fracture. This technique showed difficulties to characterize the particles 